\title{
Modelling and Simulation of Integrated Topology of DC/DC converter for LED Driver Circuit
}

\author{
DEEPAK AGRAWAL, RAJNEESH KUMAR KARN, DEEPAK VERMA, RAKESHWRI AGRAWAL \\ Birla Institute of Technology, Jaipur, Rajasthan, INDIA
}

\begin{abstract}
With the increase in technological advancements and impetus to work for the reduction of electrical energy consumption among different types of consumers, there is a primary need to take into account all forms of energy efficiency improvement methods available for electric and electronic equipment been used. It has been noticed that in commercial lighting, in terms of efficiency light-lamps based on light-emitting diodes(LEDs) are far better as compared to those where traditional high pressure sodium (HPS) lamps which are still in use in major underdeveloped and developing areas worldwide in specifically street lighting. The LED have numerous advantages such as high luminous efficiency, life span and it has no mercury in its composition. Therefore, recently researchers of this area has been setting a goal to utilize LED as a good alternative to save electricity from major parts of this planet. In this paper simulation of LED driver circuit is presented to utilize the $12 \mathrm{~V}$ LED lighting strip which has been used in Indian hawkers/small shopkeepers since a long time.
\end{abstract}

Keywords - LED, Commercial lighting, Driver circuit, PFC, MATLAB/Simulink.

Received: June 24, 2019. Revised: December 19, 2019. Accepted: January 9, 2020.Published: January 30, 2020.

\section{Introduction}

There are more than 10 million Indian hawker/street vendors according to Ministry of Housing and Urban Poverty Alleviation [1], lighting is a major issue for them. Most of them are using 12 volt LED lights as they do not have the regular electrical supply. 12 volt LED is preferred as the 12 volt battery used in vehicles is easily available in the market. In the current scenario many researchers have been setting a goal to utilize LED lifespan with efficient and good driver circuit. Driver circuits provides the supply for the LED lamps, these circuits must be compatible enough so that they can convert electrical energy from the line and supply and process it with continuous current to the LED lights. Also, the driver lifespan and LEDs lifespan must be coherently maintained, so that lamps do not lose any of its main features, especially its own lifetime factor. W. Yang et al [2] presented a highly efficient multiple-output buck-type led driver which uses only single-inductor. Various buck converter based topology is also found in literature $[3,4,5,6$, $7,8,9]$. Power factor improvement is the main concern of the researcher working in this area, some of the researcher suggested topologies with improved power factor $[9,10]$. Electrolytic Capacitor-Free topology is also available in literature which improves the lifetime of the driver $[11,4,12$, 13, 10, 14, 15, 16]. Amongst the esteemed researcher Cassio Gobbato et al [17] presented Integrated Topology of DC/DC Converter for LED Street Lighting System. This topology has been simulated and presented in this paper for 12 Volt LED lights. Topology presented in [17] is implemented as it is but the design parameters has been modified in accordance with the Indian scenario.

\section{Implemented Topology}

The topology given in [17] is implemented in MATLAB Simulink in this paper and the circuit diagram of this topology is given in Fig. 1.

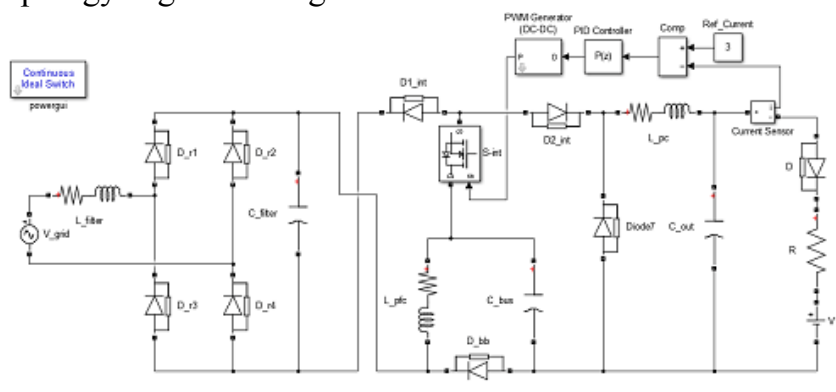

Fig. 1. Circuit diagram of integrated DC/DC converters [17].

The electrical modeling of LED as shown in the Fig. 2 is a series connection of an ideal diode (D), a resistor (R) and a voltage source (V). Voltage source characterizes the minimum voltage required to make LED forward biased .

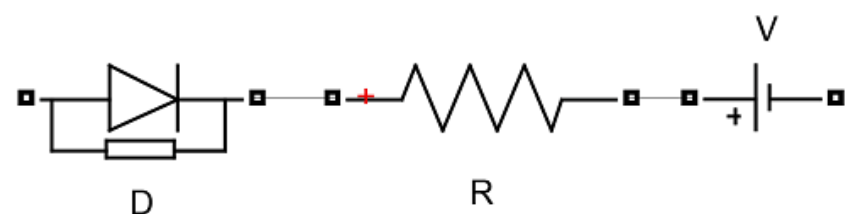

Fig. 2. Electrical modeling of LED in MATLAB Simulink

Integrated topology [17- 18]: Quanming Luo et al [18] present Single-Stage AC-DC LED Driver which is integration of two DC/DC converters. First power factor correction (PFC) unit which is Buck-Boost converter operating in discontinuous conduction mode (DCM) and second is an isolated DC/DC unit with a voltage rectifier. This integration is possible by sharing the same power switch and both the converters must operate in same duty ratio and same switching frequency. T-type inverted presented in [17] and [18] shown in Fig. 1 is the series connection of buck-boost and buck converters shown in Fig. 3 and Fig. 4. 
In this topology the drains of the switches $S_{b b}$ and $S_{b}$ share the same node thus replacing the $S_{b b}$ and $S_{b}$ switches by $S_{\text {int }}$ switch and adding two diodes $D_{\text {lint }}$ and $D_{2 i n t}$ as shown in Fig. 1.

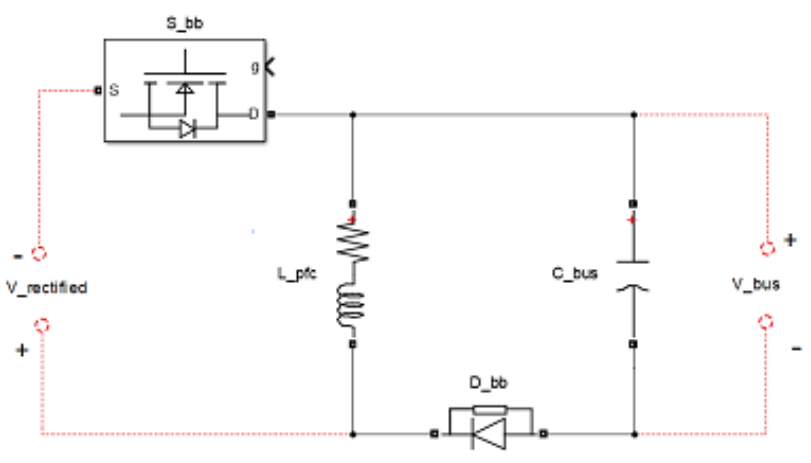

Fig. 3. Buck-boost converter

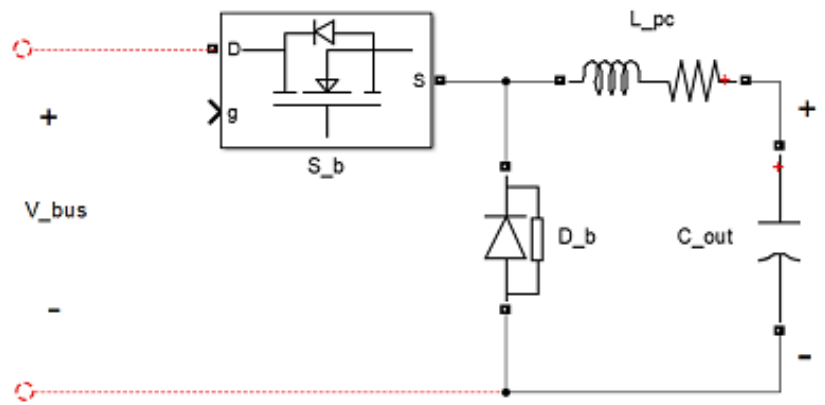

Fig. 4. Buck converter

\section{Design Parameters}

Design parameters used in the base paper [17] is shown in table 1 below:

Table- I: Design parameters used in [17]

\begin{tabular}{|l|l|l|}
\hline \multicolumn{1}{|c|}{ Symbol } & \multicolumn{1}{c|}{ Specification } & \multicolumn{1}{c|}{ Value } \\
\hline$V_{\text {GRID }}$ & Mains voltage (RMS) & $127 \mathrm{~V}$ \\
\hline$f r$ & Mains frequency & $60 \mathrm{~Hz}$ \\
\hline Po & Output power (each module) & $25 \mathrm{~W}$ \\
\hline Ileds & Average Output current & $500 \mathrm{~mA}$ \\
\hline Vbus & Average PFC output voltage & $170 \mathrm{~V}$ \\
\hline Vout & Average PC output voltage & $51 \mathrm{~V}$ \\
\hline$\Delta$ Ileds & LEDs current ripple & $100 \mathrm{~mA}-20 \%$ \\
\hline$\Delta$ Vbus & PFC output voltage ripple & $85 \mathrm{~V}-50 \%$ \\
\hline$\Delta$ Vout & PC output voltage ripple & $1.02 \mathrm{~V}-2 \%$ \\
\hline fs & Switching frequency & $60 \mathrm{kHz}$ \\
\hline
\end{tabular}

Design parameters shown in table 1 are modified according to Indian hawker/street vendors lighting requirements. As discussed in the introduction section Indian hawkers already using $12 \mathrm{~V}$ LED lights which are directly connected to a $12 \mathrm{~V}$ battery. The LED driver presented in this paper also uses 12 $\mathrm{V}$ output to fulfill the hawkers lighting demand. The LED strip or light can be used directly with $12 \mathrm{~V}$ battery when grid is unavailable and once the grid is available one can used this driver to light the same LED. The modified design parameters used in this paper is shown in table 2 .

Table- II: Design parameters used in this paper

\begin{tabular}{|l|l|l|}
\hline Symbol & \multicolumn{1}{|c|}{ Specification } & \multicolumn{1}{c|}{ Value } \\
\hline$V_{\text {GRID }}$ & Mains voltage (RMS) & $230 \mathrm{~V}$ \\
\hline$f r$ & Mains frequency & $50 \mathrm{~Hz}$ \\
\hline Po & Output power & $25 \mathrm{~W}$ \\
\hline Ileds & Average Output current & $2.2 \mathrm{~A}$ \\
\hline Vbus & Average PFC output voltage & $85 \mathrm{~V}$ \\
\hline Vout & Average PC output voltage & $12 \mathrm{~V}$ \\
\hline$\Delta I l e d s$ & LEDs current ripple & $100 \mathrm{~mA}-20 \%$ \\
\hline$\Delta$ Vbus & PFC output voltage ripple & 85.6 to $87.6 \mathrm{~V}(2.35 \%)$ \\
\hline$\Delta$ Vout & PC output voltage ripple & $\begin{array}{l}12.356 \text { to } 12.346- \\
(0.08 \%)\end{array}$ \\
\hline fs & Switching frequency & $60 \mathrm{kHz}$ \\
\hline
\end{tabular}

\section{Simulation and Results}

MATLAB Simulation of the integrated topology is presented in Fig. 1; results are discussed in this section. Fig. 5 shows the time response of load current, it shows the current is stable at the value of $2.25 \mathrm{~A}$.

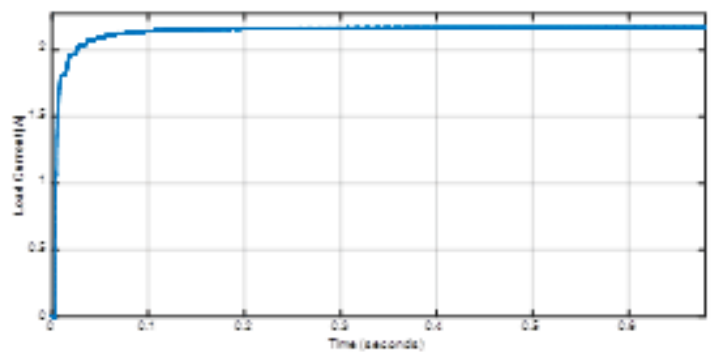

Fig. 5. Load current vs time curve

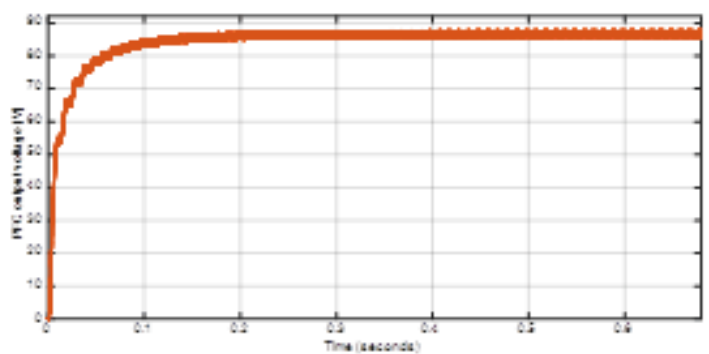

Fig. 6.a PFC output voltage vs time curve

Fig. 6.a, 6.b shows the output voltage after PFC stage and Fig. 7 shows the ripple in voltage after PFC stage. 


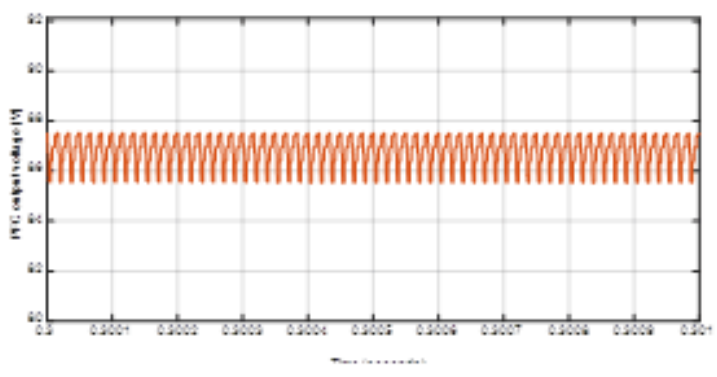

Fig. 6.b Ripple in PFC output voltage.

Fig. 7 shows the output power with respect to time plot which is stable near the 25.25 watts. This power is sufficient for the lighting purpose of the Indian hawkers.

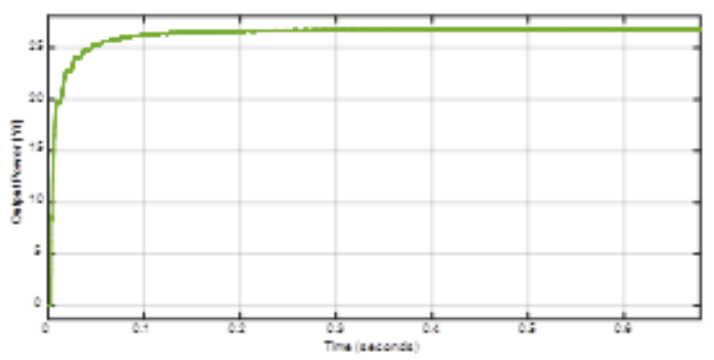

Fig. 7. Output power vs time curve.

Fig. 8 shows the output voltage at the LED end which is stabled at 12 Volts.

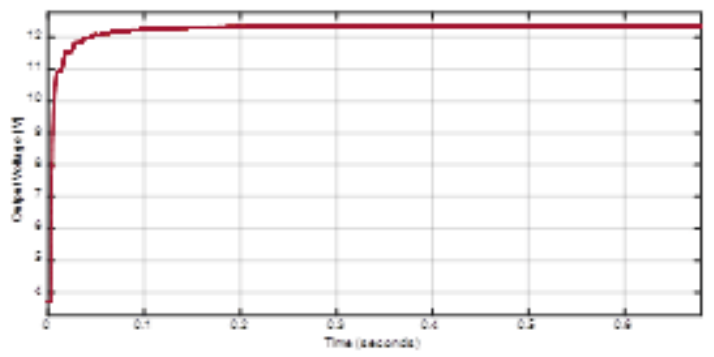

Fig. 8. Output voltage vs time curve.

Fig. 9 shows the ripple in the output voltage which is less than $1 \%$ hence the minimum flickering occurs in the LED light.

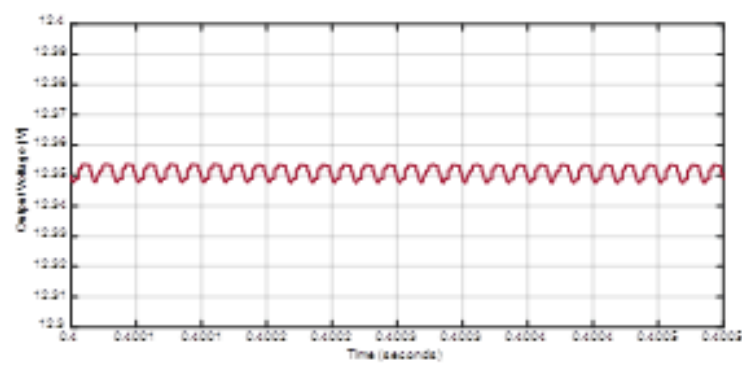

Fig. 9. Ripple in output voltage.

\section{Conclusion}

In this paper integrated topology of $\mathrm{DC} / \mathrm{DC}$ converter is presented for LED driver circuit, this topology has been presented by Cassio Gobbato et al however the designed parameters have been changed in accordance with the Indian hawker/street vendors. About 10 million Indian hawker/street vendors in India having irregular power supply. The topology is modified in accordance with them and the output voltage is stabled at 12 Volt DC which can fulfill their lighting needs with less than $1 \%$ ripples in the output.

\section{References}

[1] Ministry of Housing and Urban Poverty Alleviation, "http://mohua.gov.in".

[2] W. Yang, H. Yang, C. Huang, K. Chen and Y. Iin, "A High-Efficiency Single-Inductor Multiple-Output Buck-Type IED Driver With Average Current Correction Technique," in IEEE Transactions on Power Electronics, vol. 33, no. 4, pp. 3375-3385, April 2018.

[3] G. Z. Abdelmessih, J. M. Alonso and W. Tsai, "Analysis and Experimentation on a New High Power Factor Off-Iine IED Driver Based on Interleaved Integrated Buck Flyback Converter," in IEEE Transactions on Industry Applications, vol. 55, no. 4, pp. 4359-4369, July-Aug. 2019.

[4] C. Shin et al., "Sine-Reference Band (SRB)-Controlled Average Current Technique for Phase-Cut Dimmable AC-DC Buck IED Iighting Driver Without Electrolytic Capacitor," in IEEE Transactions on Power Electronics, vol. 33, no. 8, pp. 6994-7009, Aug. 2018.

[5] D. Do, H. Cha, B. L. Nguyen and H. Kim, "Two-Channel Interleaved Buck LED Driver Using Current-Balancing Capacitor," in IEEE Journal of Emerging and Selected Topics in Power Electronics, vol. 6, no. 3, pp. 1306-1313, Sept. 2018.

[6] G. Z. Abdelmessih, J. M. Alonso and M. A. Dalla Costa, "Loss Analysis for Efficiency Improvement of the Integrated Buck-Flyback LED Driver," in IEEE Transactions on Industry Applications, vol. 54, no. 6, pp. 6543-6553, Nov.-Dec. 2018.

[7] M. Kim, "High-Performance Current-Mode-Controller Design of Buck LED Driver With Slope Compensation," in IEEE Transactions on Power Electronics, vol. 33, no. 1, pp. 641-649, Jan. 2018.

[8] Y. Wang, S. Gao, S. Zhang and D. Xu, "A Two-Stage Quasi-Resonant Dual-Buck LED Driver With Digital Control Method," in IEEE Transactions on Industry Applications, vol. 54, no. 1, pp. 787-795, Jan.-Feb. 2018

[9] X. Liu, Y. Wan, Z. Dong, M. He, Q. Zhou and C. K. Tse, "Buck-Boost-Buck-Type Single-Switch Multistring Resonant LED Driver With High Power Factor and Passive Current Balancing," in IEEE Transactions on Power Electronics, vol. 35, no. 5 , pp. 5132-5143, May 2020

[10] H. Dong, X. Xie, L. Jiang, Z. Jin and X. Zhao, "An Electrolytic Capacitor-Iess High Power Factor LED Driver Based on a "One-and-a-Half Stage" Forward-Flyback Topology," in IEEE Transactions on Power Electronics, vol. 33, no. 2, pp. 1572-1584, Feb. 2018.

[11] J. Liu, H. Tian, G. Liang and J. Zeng, "A Bridgeless Electrolytic Capacitor-Free LED Driver Based on Series Resonant Converter With Constant Frequency Control," in IEEE Transactions on Power Electronics, vol. 34, no. 3, pp. 2712-2725, March 2019.

[12] H. Wu, S. Wong, C. K. Tse and Q. Chen, "A PFC Single-Coupled-Inductor Multiple-Output LED Driver Without Electrolytic Capacitor," in IEEE Transactions on Power Electronics, vol. 34, no. 2, pp. 1709-1725, Feb. 2019.

[13] H. Wu, S. Wong and C. K. Tse, "A More Efficient PFC Single-Coupled-Inductor Multiple-Output Electrolytic Capacitor-Iess LED Driver With Energy-Flow-Path Optimization," in IEEE Transactions on Power Electronics, vol. 34, no. 9, pp. 9052-9066, Sept. 2019.

[14] P. Fang, S. Webb, Y. Liu and P. C. Sen, "Single-Stage LED Driver Achieves Electrolytic Capacitor-Less and Flicker-Free Operation With Unidirectional Current Compensator," in IEEE Transactions on Power Electronics, vol. 34, no. 7, pp. 6760-6776, July 2019. 
[15] S. Pervaiz, A. Kumar and K. K. Afridi, "A Compact Electrolytic-Free Two-Stage Universal Input Offline LED Driver With Volume-Optimized SSC Energy Buffer," in IEEE Journal of Emerging and Selected Topics in Power Electronics, vol. 6, no. 3, pp. 1116-1130, Sept. 2018.

[16] C. Ye, P. Das and S. K. Sahoo, "Inductive decoupling-based multi-channel LED driver without electrolytic capacitors," in IET Power Electronics, vol. 12, no. 11, pp. 2771-2779, 1892019.

[17] C. Gobbato, S. V. Kohler, I. H. de Souza, G. W. Denardin and J. d. P. Iopes, "Integrated Topology of DC-DC Converter for LED Street Lighting System Based on Modular Drivers," in IEEE Transactions on Industry Applications, vol. 54, no. 4, pp. 3881-3889, July-Aug. 2018.

[18] Q. Luo, J. Huang, Q. He, K. Ma and L. Zhou, "Analysis and Design of a Single-Stage Isolated AC-DC LED Driver With a Voltage Doubler Rectifier," in IEEE Transactions on Industrial Electronics, vol. 64 , no. 7, pp. 5807-5817, July 2017. 